\title{
O CICLO VICIOSO DE DESLOCAMENTOS FORÇADOS E A FORMAÇÃO DE ESPAÇOS INCOMPLETOS EM MOÇAMBIQUE
}

\author{
THE VICIOUS CYCLE OF FORCED DISPLACEMENTS AND THE FORMATION OF INCOMPLETE SPACES IN MOZAMBIQUE
}

\section{RESUMO}

Este artigo baseou-se em vários estudos realizados pela autora sobre Migracões Forçadas em Moçambique e, apresenta a radiografia de um país com espaços habitacionais resultantes da conjugação de fatores político-militares, desastres naturais, projetos de desenvolvimento e de imigrações internacionais. Moçambique é um país da África Austral situado na costa oriental de África. É banhado pelo Canal de Moçambique em uma extensão de $2700 \mathrm{Km}$. Desde que ficou independente de Portugal em 1975, tem sofrido metamorfoses significativas em seu espaço geográfico, originadas por fenômenos cíclicos de desastres naturais, por eventos político-militares, sociais e econômicos que não permitem que a sua população não conheça o real significado de sedentarismo com o aparecimento da chamada População Deslocada Internamente e população refugiada. Após a sua independência, o país adotou uma "política hospitaleira" de acolhimento dos povos em fuga de países de regimes opressores, como são os casos do Chile, Rodésia do Sul (atual Zimbabwe) e África do Sul. Pela sua localização geográfica e pelo fato de ter experimentado uma paz militar entre 1992 e 2013, o país passou também a receber requerentes de asilo e refugiados, particularmente da região dos Grandes Lagos de África e do Corno de África, além de investidores ou pretensos investidores provenientes de várias partes do mundo com destaque para a África, Ásia Menor, Europa, China, América do Norte e Brasil que em muito contribuíram para a configuração espacial de Moçambique. Importa referir que a população imigrante e em 'fuga' raramente fixa "raízes" nos países de acolhimento, razão pela qual é possível observar em quase todo o território nacional a existência de lugares cuja ocupação reflete cenários de projetos não concluidos (ruínas) e infraestruturas destruídas ou inacabadas. Por exemplo, no Sul de Moçambique o Distrito de Xai-Xai e o projeto de areias pesadas, no Centro de Moçambique nos Distritos de Manica e Sofala e no Norte de Moçambique no Distrito de Mandimba, na Província de Niassa. Os projetos de desenvolvimento em curso, espelham sem dúvidas a emergência de um país em conflitos permanentes e em reconstituição. Trata-se de um processo vicioso e cíclico que, ao longo do tempo aqui considerado, faz surgir espaços habitacionais de construção e de destruição/desconstrução, razão pela qual os chamamos espaços incompletos/inacabados.

Palavras-chave: Migrações. População Deslocada Internamente. Refugiados. espaços incompletos.

\section{ABSTRACT}

This article is based on various studies undertaken by the author on Forced Migrations in Mozambique and it introduces to the radiography of a country, which has brought forth housing spaces deemed incomplete, that have resulted from a combination of political-military tensions, natural disasters, development projects and international migration trends. Mozambique is a Southern African country, located in the southern East side of the continent. The Channel of Mozambique lies in east coast limit zone of Mozambique in an extension of $2700 \mathrm{Km}$ stretch. Since its independence from Portugal in 1975, the country has undergone through some significant metamorphoses in its geographical territorial space, originated by cyclical natural disasters, political and military events; social and economic factors that hindered development and made people not realize the true meaning of sedentary, as there is an emergency call towards Internally Displaced persons and refugees. It is on record that upon its independence, the country adopted a "hospitable policy" of hosting people that were escaping from oppressive regimes such as "the likes" of Chile, former Southern Rhodesia (currently Zimbabwe), East Timor and South Africa. Due to geographical location factors and the fact that the country enjoyed military peace between 1992 and 2013, Mozambique played an
Inês M. Raimundo ${ }^{a}$

${ }^{a}$ Universidade Eduardo Mondlane (UEM), Maputo, Moçambique

DOI: $10.12957 /$ geouerj.2020.53912

Correpondência: inesmacamo@gmail.com

Recebido em: 10 out. 2019

Revisado em: 9 fev. 2020

Aceito em: 15 mai. 2020 
Raimundo

important role in hosting asylum seekers and refugees from the Region of Great lakes of Africa and the Horn of Africa, apart from investors and those who pretended to be investors, the country saw an influx of people from different parts of the world, Africa being the main contributor, Middle East, Europe, China, North America and Brazil have contributed to the spatial shape of Mozambique. It is important to refer that the immigrant population and those that are fleeing rarely fixe their "roots" in hosting countries. The reason being, it is possible to observe in all national territory the existence of places which reflects the reminiscent of a war thorn scenario, which either construction buildings are not yet concluded or are partially destroyed. The example of such, for instance the City of Xai-Xai in Southern Mozambique, with the heavy sand project, the province of Sofala and the unfinished Sugar plantation project while in Mandimba district in northern Mozambique, a place filled with ruins. The development projects in course reflect without a doubt the emergency character of a country with never-ending conflicts and under reconstruction. It is about a vicious cycle that along time remained an obstacle in allocating, housing spaces for construction purposes and for that I call incomplete spaces or unfinished spaces.

Keywords: Migrations; Internally Displaced Persons; Refugees; incomplete spaces 


\section{INTRODUÇÃO}

Moçambique tem longa história de migrações forçadas em ambos sentidos: como país "emissor "e "receptor" assim como deslocamentos forçados internos resultantes de causas de ordem natural (cheias, ciclones, secas e aluimento de terras), políticos (guerras), econômicos (projetos de desenvolvimentos incluindo aldeias comunais, operação produção e campos de reeducação) ${ }^{1}$ e sociais (acusações de feitiçaria ${ }^{2}$ ). Estes movimentos têm criado ao longo dos anos populações nómadas que, literalmente vivem a vida de cágado. Isto é, levam a sua casa às costas, e de certa maneira, nunca criando espaços e nem garantindo resiliência após o choque. Do xibalo³, a Guerra de libertação, a Guerra de 16 anos (1976-1992), os conflitos pós Assinatura de Acordos de Paz (1992), nomeadamente as hostilidades militares (Setembro de 2014) cujo acordo de cessação foi assinado em Maputo no dia 5 de Setembro 2014, as calamidades naturais e os projetos de desenvolvimento têm sido algumas das causas de deslocações forçadas de moçambicanos dentro do país assim como fora dele. Porém, não obstante esta longa história de deslocamentos forçados de moçambicanos, o país tem, também, experiência de acolher de pessoas que procuram asilo em decorrência de instabilidades políticas nos seus países de origem. Vale afirmar que este processo não é novo, mas vem acontecendo com maior ou menor intensidade dependendo do momento em que o país vive ou viveu. A população deslocada por eventos naturais, ou mesmo por eventos políticos e econômicos é bastante variável. Por exemplo, não se sabe ao certo quantas pessoas foram refugiadas na Tanzânia, mas informação sobre as cheias do Rio Zambeze indicam que "Até terça-feira, o número de pessoas "refugiadas "pelas cheias no vale do Zambeze, centro de Moçambique, era de $77.150^{\prime \prime}$

O país acolheu militantes do ANC, do Chile ${ }^{5}$, da antiga Rodésia do Sul (ZANU-FP ), do Timor Leste e mais, recentemente, pessoas oriundas da região dos Grandes Lagos da África Oriental e do chamado Corno de África. As fugas e subsequentes pedidos de asilo estão relacionados com várias causas: uns fugiam de seus países no contexto de lutas de libertação, são exemplos os combatentes do ANC que lutavam contra o regime do Apartheid e os Zimbabueanos que fugiam contra a repressão do então regime da Rodésia do Primeiro-ministro Ian Smith.

Outros fugiam das ditaduras militares, como do General Augusto Pinochet do Chile e os Timorenses, que lutavam contra a ocupação por parte da Indonésia. Muito recentemente, o país passou a partir dos anos

\footnotetext{
1 Vide Raimundo (2009a).

2 Sobre este assunto vide Raimundo (2009b).

3 Em língua changana (uma das línguas faladas no Sul de Moçambique) significa trabalho forçado.

${ }^{4}$ Segundo porta-voz do Centro Nacional Operativo de Emergência, Belarmino Chivambo (Fevereiro de 2014).

${ }^{5}$ Que fugiam da ditadura do General Augusto Pinochet.

${ }^{6}$ Zimbabwe African National Union-Patriotic Front (União Nacional Africana do Zimbabwe-Frente Patriótica).
} 
1990 a receber outro tipo de requerentes de asilo, provenientes da Região dos Grandes Lagos da África Oriental e do Corno de África. Fogem também de genocídios sendo o caso a situação de Burundi em 1994.

Finamente, o país passou a receber outra categoria de imigrantes forçados, por razões de ordem econômica, são os casos de populações da Nigéria, Líbano e Paquistão. Estes últimos, em estudos realizados no contexto do movimento transfronteiriço $(\mathrm{SAMP})^{7}$ alegam que usam Moçambique como país de trânsito para a África do Sul.

O que torna particular esta situação é o fato do país assumir duplos papéis: emissor de refugiados e receptor de refugiados e, ao mesmo tempo um país que a sua população é internamente devastada por fenômenos naturais tais como secas, cheias e aluimento de terras que provocam deslocamentos permanentes. Por outro lado, é preciso mencionar que outros movimentos forçados no período pós-independência de Moçambique provocaram movimentações de grupos populacionais. São as Aldeias Comunais, as reeducações dos considerados contrarrevolucionários e finalmente a Operação Produção.

Este artigo procura trazer os desafios encontrados no processo de formação do espaço em Moçambique no contexto das permanentes deslocações populacionais forçadas internas e internacionais. Tal como em qualquer processo de reassentamento conflitos são inevitáveis, nomeadamente a falta de vontade em mudar de lugar, porque já se integraram, porque estão próximos da "civilização" ${ }^{8}$, ou porque correm perigo em outro lugar. Assédios psicológicos e físicos são reportados pelas pessoas que são obrigadas a mudar de seu lugar no contexto de reassentamento.

O cenário descrito sobre constantes deslocações levaram-nos a concluir que em Moçambique o povo não é sedentário e convive com povos não sedentários. Qualquer povo em contato com a natureza vai criando e organizando o seu espaço produtivo e de residências. E nas condições de deslocamentos dificilmente se constituem espaços acabados. Por isso o questionamento sobre o conceito de população sedentária.

Dados empíricos de vários anos e histórias de vida de pessoas que convieram com refugiados ou pessoas refugiadas foram usados para a elaboração deste artigo, assim como dados de estudos realizados no contexto de pesquisas sobre Deslocamentos Populacionais no âmbito das cheias em Moçambique, particularmente o caso do Rio Limpopo. $O$ artigo deve ser entendido como reflexões sobre os processos inacabados de criação do espaço e da incapacidade de criar resiliência após choque. Concluindo, os espaços são flexíveis e

\footnotetext{
7 Southern Africa Migration Project-Projecto das Migrações da África Austral. Fazem parte deste projeto as universidades de Witwatersrand, Johannesburg (África do Sul), Zimbabwe, Eduardo Mondlane, Namíbia, Swazilânida, Malawi, Botswana e Queen's do Canadá.

${ }^{8}$ As pessoas entrevistadas entendem por civilização tudo que tem a ver com existência de electricidade, água canalizada, estradas, edifícios altos e acesso a salas de cinema.
} 
incompletos, existem em função dos contextos e dos fatores de 'stress'. É um constante desafio contra a natureza, a política, o desenvolvimento e a governança.

\section{LOCALIZAÇÃO GEOGRÁFICA DE MOÇAMBIQUE: DIREITOS CONSTITUCIONAIS E PROTEÇÃO}

A República de Moçambique é um país localizado na África Austral e limitado pela República da África do Sul e o Reino da Suazilândia a Sul, pelas Repúblicas do Malawi, Zâmbia e Zimbabwe a Oeste e banhado pelo Oceano Índico em toda a costa Este em uma extensão de cerca de 2.700Km (Atlas Geográfico Volume I 1986). Possui uma superfície de $799.380 \mathrm{~km} 2$ de terra firme e $13.000 \mathrm{Km} 2$ de águas superficiais e interiores (INGC et al 2003; 2011).

Ainda de acordo com o INGC et al, o seu relevo é designado por relevo em escadaria, pois da costa ao interior apresenta planícies, planaltos e montanhas. A localização geográfica entre o Oceano Índico e o Grande plateau central africano e a sua variada topografia contribui para que a temperatura e a precipitação sejam variadas à medida em que nos dirigimos da costa para o interior ou vice-versa. Os rios de Moçambique nascem no interior e desaguam no canal de Moçambique e esta situação hidrográfica torna o país bastante vulnerável às cheias e inundações. O maior rio de todos é o Zambeze, onde foi construída a Barragem de Cabora Bassa. Entretanto, existem outros rios de dimensão regional. São os casos de Rovuma, Lúrio, Licungo, Púngoè, Búzi, Save, Limpopo e Incomáti.

A Constituição da República de Moçambique (Artigo 7 sobre Organização Territorial) diz que a República de Moçambique organiza-se territorialmente em províncias, distritos, postos administrativos, localidade e povoações. No ponto 2 diz que as zonas urbanas estruturam-se em cidades e vilas. Assim, são no total 11 províncias (incluindo a Cidade de Maputo com estatuto de província). São do norte para o sul as seguintes províncias: Cabo Delgado, Niassa, Nampula, Zambézia, Tete, Manica, Sofala, Inhambane, Gaza, Maputo Província e Cidade de Maputo. A capital é a Cidade de Maputo. A mesma Constituição dá iguais direitos a homens e mulheres. Sendo que desenvolve e aprofunda os princípios fundamentais do Estado moçambicano, consagra o carácter soberano do Estado de Direito Democrático, baseado no pluralismo de expressão, organização partidária e no respeito e garantia dos direitos e liberdades fundamentais dos cidadãos.

No que se refere a proteção em caso de acidentes ou de desastres a Lei no 15/2014 estabelece o regime jurídico da gestão das calamidades, compreendendo a prevenção, mitigação dos efeitos destruidores das calamidades, desenvolvimento de ações de socorro e assistência, bem como as ações de reconstrução e recuperação das áreas afetadas (Boletim da República 2014)9:

\footnotetext{
9 Boletim da República, 20 de Junho de 2014, I Série No 50, Imprensa Nacional de Moçambique, E.P.
} 
Figura 1. República de Moçambique. Fonte: Raimundo (2010).

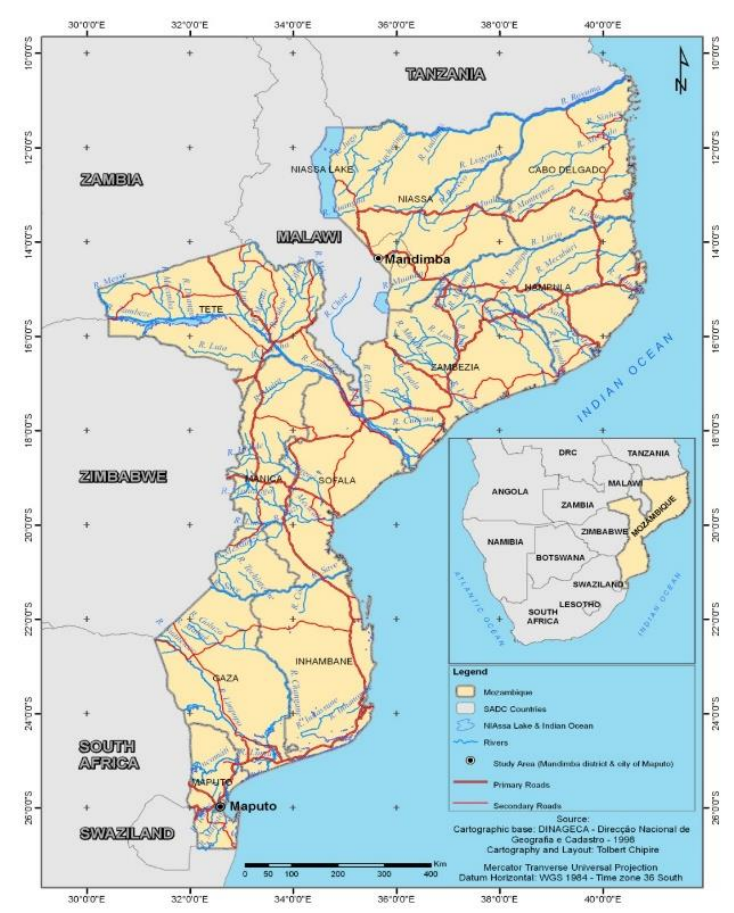

Foi previamente mencionado que Moçambique no conjunto dos países da África Austral é o que mais tem sido afetado por desastres naturais, sendo que, os que mais têm afetado Moçambique são ciclones, inundações e secas. Estes últimos conhecidos por fenómeno silencioso, pois os efeitos são visíveis depois de algum tempo. Os desastres naturais têm um impacto desastroso sobre a economia nacional e sobre a população e, em consequência na interrupção de espaços e, ou na criação de resiliência. Tudo isto porque estes eventos têm sido classificados como anuais porque acontecem cerca de 1,17 vezes durante o ano (INGC et al 2012). Por exemplo, as cheias de 2000 e 2013 desalojaram entre 500 mil e 650 mil pessoas nas províncias de Inhambane, Gaza e Maputo e 186 mil pessoas desalojadas nos distritos de Chókwè, Guijá, Chibuto e XaiXai na província de respectivamente (GFDRR, World Bank, EU, UNDP e INGC $\left(2014\right.$, p. 7) ${ }^{10}$.

A relativa elevada frequência assim como, o intervalo de tempo curto, e a elevada intrepidez dos desastres, não dão tempo suficiente para a reconstrução das infraestruturas e assistência eficaz às famílias, no qual, milhares destas ficam à mercê dos desastres e, se encontram por isso, em situação de extrema vulnerabilidade.

É de referir que os desastres se alternam. Por exemplo, quando ocorrem cheias em uma região, a outra é afetada pelas secas. Recentemente, foi a situação que se observou nas regiões do centro e do sul. Em 2015

\footnotetext{
10 Título: A recuperação de cheias recorrentes 2000-2013: Estudo do Caso para o quadro de recuperação de desastres. In: Série de
} estudos de casos nacionais/Guião para o Quadro de Recuperação de desastres/Agosto 2014. 
e 2016, enquanto a região centro constituída pelas províncias da Zambézia, Manica, Sofala e Tete sofriam cheias destruidoras as províncias do sul constituídas por Inhambane, Gaza, Maputo e Cidade de Maputo registavam secas, de tal forma, por exemplo, que cerca de 120.300 pessoas, encontravam-se em situação de insegurança alimentar, e, por isso, a necessidade em assistência alimentar urgente (Mondlane 2017).

No conjunto das 11 províncias de Moçambique, a região central é a mais populosa, e a que mais sofre por causa dos fenômenos de cheias que ocorrem na Bacia do Zambeze. As cheias são responsáveis por quase um terço de todos os prejuízos econômicos e são mais difíceis de avaliar em termos de impacto. Estudiosos dos assuntos sobre inundações dizem que as cheias, apesar de serem potencialmente destrutivas, também trazem consigo benefícios. Dentre os benefícios se encontram os processos regenerativos do ciclo ecológico, fertilização dos solos, reabastecimento dos aquíferos subterrâneos, gerar abundância de peixe e incremento de rendimentos agrícolas.

Sobre o assunto, no estudo sobre "Gender disaster management" realizado na província de Gaza em 2001 (Raimundo 2001) nas entrevistas realizadas na Aldeia da Barragem, algumas das pessoas entrevistadas, disseram que "as cheias tinham trazido sementes de papaia e por isso, a aldeia estava cheia de papaieiras, e não sabia o que fazer com tanta papaia". Por outro lado, as mesmas cheias tinham trazido sementes de soruma. E a aldeia estava na altura a cortar essas plantas, porque a soruma trazia desgraça no seio da população.

\section{UMA HISTÓRIA DE CONSTRUÇÃO DO ESPAÇO MOLDADA POR ASSENTAMENTOS E REASSENTAMENTOS CícLICOS}

OS DESLOCAMENTOS PROVOCADOS POR FENÔMENOS NATURAIS: CICLOS, CHEIAS, SECAS E ALUIMENTO DE TERRAS

Dentro da região austral de África, Moçambique parece ser o país que mais tem sido afetado por desastres naturais e por guerras ou instabilidade política. Vejamos, em 40 anos foram sucessivos ciclones (Demoina 1984; Filão 1988; Nádia 1994; Bonita 1996; Lisette 1997; Elinne 2000; Glória 2000 e Hudah 2000) devastadores que deslocaram milhares de pessoas (UEM-FEWSNet, 2002). Por exemplo, as inundações do Rio Zambeze ocorridas entre 2007 e 2010 obrigaram o governo de Moçambique a reassentar 59 mil famílias (Millan, 2015:54) $)^{11}$. A figura 2, ilustra a hidrografia de Moçambique. Os mesmos rios que do Rovuma (extremo Norte) até Maputo (extremo Sul) têm provocado inundações.

\footnotetext{
${ }^{11}$ Stéphanie Millan (2015) Construction du droit des personnes déplacées internes, victimes de catastrophes naturelles. In Mobilité humaine et environnement du global au local. Editions Quae.
} 
Figura 2. Mapa hidrográfico de Moçambique. Fonte: https://www.google.fr/mapa+hidrologico+de+mocambique (acedido no dia 17/12/2017).

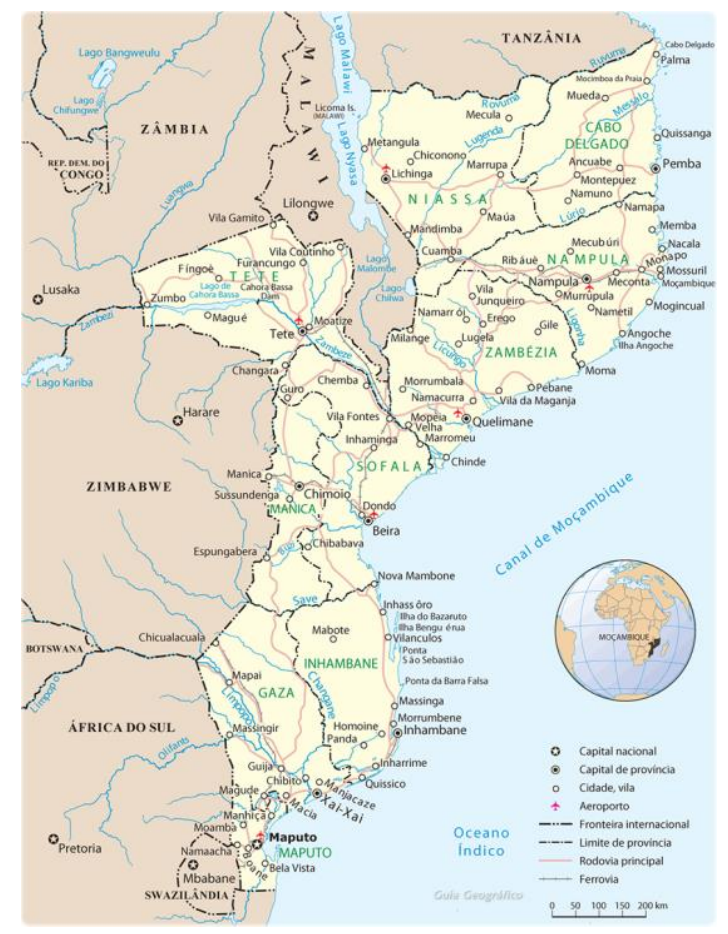

São incontáveis as pessoas deslocadas por causa das cheias dos Rios Zambeze, Buzi, Púngoè, Save, Limpopo e Incomáti assim como o efeito das secas em quase todo o país, particularmente nas províncias de Maputo, Gaza e Inhambane (sul), Sofala, Tete e Zambézia (centro).

O INGC et al (2012) diz que nas cheias dos anos 2000 e 2001 foram desalojadas mais de 500.000 pessoas e destruídas importantes infraestruturas sociais e econômicas. Na altura, os custos associados a esses desastres naturais ascenderam a mais de 22 mil milhões de meticais (moeda moçambicana). Segundo a Afro News (2004) cerca de 54,5\% do país foi afetado pelas piores secas jamais registadas em 50 anos entre 1991 e 1992. Outras calamidades naturais que não têm sido reportadas, mas que têm provocado deslocações populacionais são os aluimentos de terras. Os mesmos têm ocorrido com alguma relativa regularidade, mas não noticiadas, porque a atenção está nas cheias e secas. Os aluimentos de terra têm ocorrido nas montanhas moçambicanas na seção do Vale do Rift, isto é nas províncias do Niassa, Zambézia, Manica e Sofala (vide figura 2).

Casos sobre aluimentos de terras reportados por causa da quantidade de pessoas que morreram são os que ocorreram em 1998 em Milange (província da Zambézia), onde morreram 73 pessoas e em Chimanimani no ano 2007 na província de Manica aonde foram registadas 16 mortes $^{12}$.

\footnotetext{
12 Informações obtidas em: http://reliefweb.int/report/mozambique/landslide-death-toll-might-hit-143 e http://www.panapress.com/Mozambique-s-landslide-kills-16,-mainly-Zimbabwean-gold-miners--13-503573-17-lang2-index.html. Acesso em: 10 de dez. de 2017.
} 
Todos estes eventos têm como impacto imediato a movimentação de famílias, ou de pessoas individualmente. Pelas razões mencionadas não existe informação precisa sobre quantas pessoas foram afetadas, e quantas foram deslocadas e onde foram realocadas. Por outro lado, é preciso mencionar que em muitos dos casos após o efeito do choque as pessoas regressam para as suas áreas originais de residência. Vale afirmar, nestas circunstâncias que ninguém se arrisca a construir uma casa definitiva e nem a criar uma produção para o futuro, pois como alguém nos relatou em Mandimba (província do Niassa) "vivemos assim durante anos, porque temos medo da guerra. Se construirmos esses vão destruir e queimar".

\section{MOBILIDADE E VIDA DE CÁGADO}

\section{A GUERRA E OS DESLOCAMENTOS}

Historicamente, os moçambicanos têm procurado refúgio nos países vizinhos, sendo o Malawi o país que tem recebido o maior número deles. Por exemplo, Babu e Hassan (1994) dizem que havia no Malawi no ano de 1989 cerca de 780 mil refugiados moçambicanos e havia 31 mil na Zâmbia e em 1992 os refugiados moçambicanos constituíam $17 \%$ da população do Malawi.

A Guerra dos 16 anos e o subsequente Acordo Geral de Paz de 1992, permitiu o retorno de cerca de 1.7 milhões de moçambicanos, que estavam exilados nos países vizinhos, sendo o maior número registado na República do Malawi (Raimundo 2010; Bruck 1998).

Tabela 1: Estimativas de População Deslocada e Refugiada Fonte: Bruck (1989: quadro 5, página 11)13.

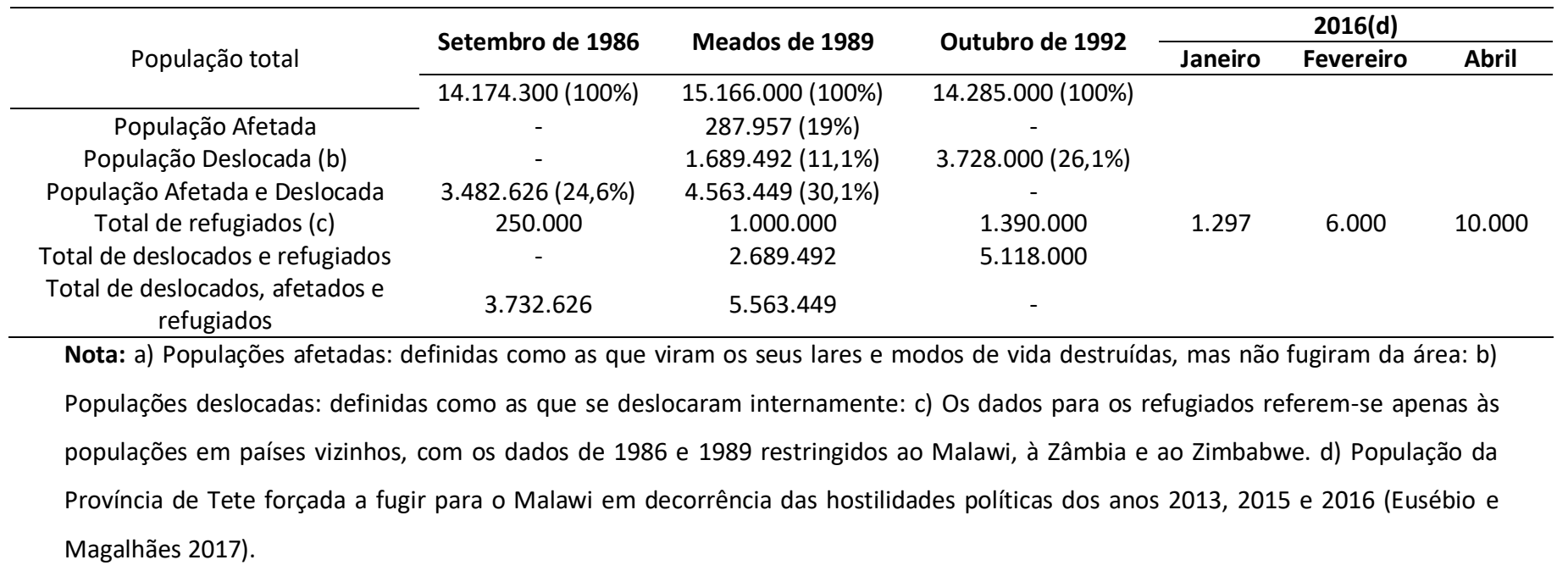

13 Título: Guerra e desenvolvimento em Moçambique. Análise Social, vol. XXXIII (149), 1998 (5), 1009-1051). Tilman Bruck. 
As famílias regressadas procuraram por vários meios reorganizar as suas vidas, seja nas antigas aldeias de onde oram originárias, sejam em cidades tais como os casos de moçambicanos que se encontraram refugiadas na África do Sul originárias de Chicualacuala que optaram por reconstruir as suas vidas nas cidades do Chókwè e Xai-Xai na província de Gaza e Maputo (Raimundo 2005; 2010).

Já foi escrito sobre a Guerra em Moçambique. Começando pela guerra de libertação que durou 10 anos, depois da independência que terminou com a assinatura do Acordo de Lusaka no dia 7 de Setembro de 1974. O acordo foi entre o Estado Português e a FRELIMO. Neste acordo, foi discutida a independência de Moçambique que veio a acontecer no dia 25 de Junho de 1975. Após a independência no meio das cheias dos Rios do sul de Moçambique estava a iniciar a guerra do dos 16 anos (1976-1992) e terminou com a assinatura do Acordo Geral de Paz em Roma no dia 4 de Outubro de 1992.

O acordo foi assinado entre o Governo da FRELIMO e a RENAMO ${ }^{14}$. Volvidos 20 anos de paz eclodiram em 2014 as chamadas hostilidades militares que consistiam em ataques armados a população da região central de Moçambique. Estas hostilidades cessaram com a assinatura do Acordo de Cessação de hostilidades no dia 5 de Setembro de 2014 na Cidade de Maputo entre o Governo da FRELIMO e a RENAMO. Entretanto, em 2015, após o anúncio dos resultados eleitorais que não foram aceites pela RENAMO e a reivindicação de governar as 6 províncias onde o partido RENAMO venceu as eleições ${ }^{15}$, o seu líder Afonso Dlakhama refugiouse nas matas de Gorongosa e de lá passou a comandar ataques militares, cujos alvos são as províncias onde alegadamente venceu as eleições.

Sobre o assunto deve-se referir que estes ataques armados apesar de matarem muitas pessoas, destruírem infraestruturas, desalojarem famílias e, por conseguinte, a origem dos refugiados e de População Deslocada Internamente, ainda não têm nome específico e o governo não aceita como guerra. O fato é que a imprensa nacional e internacional tem mencionado os ataques e a existência de um número incontável de população refugiada no Malawi. As fontes não oficiais dizem que o Malawi ${ }^{16}$ aceitou reabrir o campo de refugiados de Luwani para receber moçambicanos em fuga devido à guerra. Refere-se que Luwani foi refúgio de muitos refugiados durante a guerra civil. O fato é que se trata de uma população que mais uma vez deixou as suas aldeias, e não pode fazer agricultura ou outra atividade econômica devido à instabilidade militar. Estas populações estão condenadas a viver permanentemente o nomadismo.

\footnotetext{
${ }^{14}$ Sobre esta guerra uns chamam por civil e outros defendem que foi uma guerra de desestabilização movida pelo então regime do Apartheid da África do Sul e que inicialmente também teve apoio das Forças de Defesa Rodesianas de lan Smith (comm. Pessoal). ${ }^{15}$ As províncias em questão são: Manica, Sofala, Tete, Zambézia, Nampula e Niassa, coincidentemente são as províncias mais ricas em minerais, fauna bravia, florestas e solos mais férteis de Moçambique (Comm. Pessoal).

16 Informação tirada na internet (http://www.dw.com/pt-002/refugiados-mocambicanos-no-malawi-querem-regressar/a-19120338) diz que o Malawi acolhe em 2016 cerca de 25 mil refugiados de zonas de conflito, sobretudo da Região dos Grandes Lagos e do Corno de África, em Dzaleka, num campo perto da capital de Lilongwe, também sobrelotado. Estima-se um total de 10.000 moçambicanos provenientes da província de Tete.
} 


\section{PROJETOS DE DESENVOLVIMENTO E DESLOCAMENTOS POPULACIONAIS}

Entre 1992 até 2014 a economia de Moçambique passou a registrar indicadores positivos (vide relatórios do UNDP de 1998 até 2014) em consequência do clima de paz e da abertura aos investimentos estrangeiros. Para estes casos indicam-se as Companhias Vale do Rio Doce na exploração do carvão mineral na província de Tete, Rio Tinto, projeto ProSavana ${ }^{17}$, o gasoduto da SASOL (2003); a expansão da fundição de alumínio MOZAL II (2004); as areias pesadas de Moma, a fundição do alumínio através do projeto MOZAL (Mozambique Alumínio) e os projetos de reordenamento urbano que pressupõem a movimentação de pessoas. São projetos que levaram ou têm levado a despovoamentos populacionais.

O Sul de Moçambique, particularmente a Cidade de Maputo tem acompanhado reassentamentos, devido, a outros projetos no âmbito do melhoramento das infraestruturas de circulação. São os casos da Ponte Maputo-Catembe e a Estrada Circular de Maputo (Ring road). Sobre a Estrada Circular foram defendidas duas dissertações na Faculdade de Letras e Ciências Sociais da UEM. Uma em Geografia realizada por Bechel $(2013)^{18}$ e outra em Sociologia realizada por Manuel $(2015)^{19}$. Ambos, mencionam que a Estrada Circular de Maputo com a extensão de $74 \mathrm{Km}$, envolveu o reassentamento de cerca de 2 mil famílias, destruição de 2090 infraestruturas públicas e privadas, incluindo redes de abastecimento de água, energia, habitações e lojas, 819 machambas e 422 campas.

Estes dados levam-nos a concluir que o "desenvolvimento" é um processo de assentamento e de reassentamento. Os 41 anos de independência de Moçambique ilustram esta necessidade de assentar e de reassentar, pois, como se diz em discursos políticos “é preciso trazer desenvolvimento para as pessoas. Lutamos para trazer dignidade ao povo moçambicano".

Entretanto, Castel-Branco e Selemane ${ }^{20}$ (2001) referem que no âmbito do projeto da mineradora Vale do Rio Doce, foram transferidas entre 2009 e 2010 cerca de 1313 famílias ou cerca de 5 mil pessoas reassentadas em Cateme e Bairro 25 de Setembro na Vila de Moatize, vila onde tem lugar a exploração do carvão. Muito se falou sobre o assunto, e o mesmo foi, em certa medida, categorizado como uma das violações dos direitos humanos perpetradas pela Companhia e com a conivência do governo moçambicano ${ }^{21}$. O certo é que à semelhança dos outros fenômenos, mais uma vez vemos famílias que são movimentadas e desta vez

\footnotetext{
17 Iniciativa conjunta entre Japão, Brasil e Moçambique na zona de Savana do Corredor ferro-portuário de Nacala (Nacala, Entre-Rios e Cuamba nas províncias de Nampula e Niassa, norte de Moçambique) que inicialmente foi inspirado pelo projeto do Cerrado do Brasil entre Brasil e Japão (Shankland e Gonçalves 2016).

18 O impacto da Estrada Circular de Maputo (Round about/Ring road).

${ }^{19}$ As transformações sociais no âmbito da construção da Estrada Circular de Maputo, Caso do Bairro Intaka de 2011 a 2014.

20 Mosca e Selemane "El dorado Tete: os megaprojetos de mineração". CIP (Centro de Integridade Pública).

${ }^{21}$ Sobre o assunto, vide a carta endereçada ao Exmo. Senhor Armando Guebuza, então presidente da República de Moçambique datada de 26 de Outubro de 2012. Foram os representantes das seguintes organizações, nomeadamente a Liga dos Direitos Humanos (LDH), a Justiça Ambiental (JÁ), Associação de Apoio e Assistência Jurídica das Comunidades (AAAAJC) e União Nacional de Camponeses (UNAC) que a assinaram.
} 
não por razões naturais, mas sim por implementação de ações que, se presumem que levarão ao desenvolvimento.

\section{UMA HISTÓRIA DE CONSTRUÇÃO DO ESPAÇO MOLDADA POR ASSENTAMENTOS E REASSENTAMENTOS CÍ́CLICOS DE POPULAÇÃO DESLOCADA, REFUGIADA E REQUERENTE DE ASILO}

Tal como foi dito na celebração dos 50 anos da UNHCR ${ }^{22}$, os países africanos têm sido extremamente generosos na recepção e no acolhimento de um número elevado de população refugiada ao longo dos últimos anos do Século XX. Moçambique não é exceção, aliás o então Diretor Geral do UNHCR, Engenheiro Gutierrez na visita que realizou em Moçambique ao Campo de Refugiados de Maratane no ano 2007, disse que este era um campo amigável. A racionalidade de tal acolhimento pode ser explicada parcialmente devido à natureza africana de receber quem está em perigo, pois existem dois provérbios por detrás: i) Se a casa do vizinho estiver a arder é bom que ajudes a apagar o fogo e receber os que necessitam abrigo; ii) onde come um podem comer duas pessoas ou mais. Pelo que, não há problema em receber mais uma boca; iii) o país produz e produziu refugiados na sua história, pelo que é dever moral receber refugiados; iv) o fato de algumas das pessoas que procuram refúgio terem família em Moçambique é um meio caminho para que sejam recebidos.

A história dos campos de refugiados tem oficialmente a sua origem há alguns anos. Durante a Luta Armada de Libertação de Moçambique, a FRELIMO ${ }^{23}$ usou como estratégia as aldeias comunais, que não eram campos de refugiados, mas de alguma forma poderiam ser entendidas como tal. Porque eram lugares que serviam de forma de organização da produção agrícola, mas também como conquistas da luta armada de libertação de Moçambique. As aldeias comunais foram criadas com o objetivo de juntar população dispersa e, desta forma, garantir o fornecimento de serviços tais como saúde, educação, água, comércio e produção agrícola e, torna-las em lugares de produção agrícola, e garantir a redução da fome (Raimundo 2009; Araújo 1988; Kaplan 1985).

Se as aldeias comunais representam em nosso entender como campos de refugiados da guerra da libertação é, também de admitir que houve outros campos de refugiados ou de acomodação reconhecidos pelo Governo de Moçambique. São eles o Matola (ANC), o Campo de Refugiados de Inhazonia (Província de

\footnotetext{
22 United Nations High Commissioner for Refugees (2000) the state of the world's refugees: Fifty years of humanitarian action. Oxford University Press Inc., New York.

23 Frente de Libertação de Moçambique, movimento armado que organizou a guerrilha que lutou para a independência de Moçambique entre 1964 e 1975. O referido movimento foi fundado em 25 de Junho de 1962 (como resultado da fusão de 3 movimentos armados, nomeadamente MANU (Mozambique African National Union), UDENAMO (União Democrática Nacional de Moçambique) e UNAMI (União Nacional Africana de Moçambique Independente) e FRELIMO (Frente de Libertação de Moçambique) e a luta armada iniciou no dia 25 de Setembro e, por isso, é também o dia das Forças Armadas de Moçambique.
} 
Manica) e Xai-Xai (Província de Gaza) dos refugiados da ZANU-FP e depois sucessivamente os campos de refugiados de Bobole, Massaca e finalmente Maratane.

A tabela 2, ilustra os refugiados do Zimbabwe e da África do Sul entre 1979 e 1989. Pouca informação oficial tem-se sobre o assunto, mas pode-se observar que Moçambique acomodou mais zimbabueanos do que sul-africanos.

Tabela 2. Refugiados zimbabueanos e sul-africanos em Moçambique. Fonte: https://www.umanitoba.ca/institutes/disaster_research/refugee_thesis/chapter6.pd

\begin{tabular}{lllll}
\hline País & Países de refúgio & $1979-1980$ & $1980-81$ & $1988-89$ \\
\hline Zimbabwe & Botswana & 19.900 & 22.000 & 3.151 \\
& Moçambique & 11.000 & 72.000 & \\
África do Sul & Zâmbia & 20.000 & 21.000 & - \\
& & $1993-94$ & - & - \\
& Moçambique & 692 & - & - \\
\hline
\end{tabular}

Como foi dito antes a grande maioria dos refugiados ou requerente de asilo em Moçambique são pessoas da região dos Grandes Lagos da África oriental. Entre 1995 e 1999 eram 500 pessoas com estatuto de refugiados vivendo em Maputo, muitos deles em Bobole e Massaca. Entretanto, no ano 2001 o número subiu para 5.000, e em 2003 o número passou para 8.000 refugiados. De lá até aos dias de hoje este número foi se mantendo considerando alguns deles, beneficiaram de acolhimento em um terceiro país (INACE' 2013). Entretanto, o Jornal Notícias publicou em 2010 que entravam mensalmente em Moçambique cerca de 200 somalis que pediam asilo no país.

A UNHRC ${ }^{24}$ refere que a entrada de refugiados em Moçambique iniciou nos meados de 1970 com o agravamento de conflitos militares em África, particularmente na região Austral incluindo a luta pelas independências de Moçambique, Angola e Rodésia do Sul (Zimbabwe). No final da década de1970, a UNHRC estimou em cerca de 14.500 refugiados da antiga Rodésia do Sul que entraram em Moçambique.

Este número cresceu muito rapidamente em 1979 (um ano antes da independência da Rodésia do Sul), e estimou-se em cerca de 210.000 refugiados zimbabueanos em Moçambique, Botswana e Zâmbia. Entretanto, com a sua independência a recém-independente Rodésia do Sul que passou a designar-se Zimbabwe passou também a receber refugiados moçambicanos no contexto da reciprocidade e cumplicidade entre os países da região. Com o fim da Guerra foram repatriados do Zimbabwe cerca 250.000 refugiados moçambicanos (ver tabela 2).

24 The United Nations High Commission for Refugees. 
Os anos de contato com zimbabueanos, sul-africanos, chilenos, timorenses e outros refugiados em Moçambique terão ensinado as várias formas de organizar o espaço produtivo e de residência. Pois cada povo tem a sua forma de organizar o espaço, mas também cada povo que acolhe assimila ou não as várias formas de organização do espaço. O repatriamento destes povos após a normalização da condição de vida nos seus países terá, obviamente, deixado um espaços não concluídos à semelhança do que é deixado pelos moçambicanos durante as suas deslocações.

\section{DO CAMPO DE REFUGIADOS DE BOBOLE AO CAMPO DE REFUGIADOS DE MARATANE}

Este artigo tem como foco principal os refugiados de Bobole, e mais tarde de Maratano por serem os que tem sido mais documentados e mais estudados. E, por isso, mais possibilidades de argumentação. Os casos de refugiados do Zimbabwe, África do Sul, Chile e Timor Leste não têm sido prestados muita atenção, não obstante o governo do Zimbabwe em 2012 ter prestado uma homenagem em Moçambique às vítimas do massacre de Inhazónia em Manica onde, se alega que o regime de Ian Smith da antiga Rodésia do Sul ter massacrado no dia 23 de Novembro de 1977 cerca de 1030 pessoa no campo no contexto dos 32 anos da independência do Zimbabwe ${ }^{25}$.

Por volta de finais de 1970 a população refugiada em Moçambique atingiu o equivalente a 14500. Entretanto, com a guerra dos 16 anos o registo de refugiados foi sendo negligenciado, porque o país também tinha a sua população refugiada a viver nos países vizinhos. Depois da Assinatura do Acordo de Paz em Outubro de 1992, nos subsequentes 20 anos o país reunia condições para receber população refugada, porque havia paz efetiva sem o troar de armas.

Por outro lado, o campo de refugiados de Maratane era um campo aberto que facilitava a deslocação dos refugiados de dentro e para fora do mesmo. Consolo (2015) defende que estes movimentos eram possíveis, porque os mesmos não corriam riscos de ataques xenófobos. Vale também referir que a Lei da Migração 5/93 de 28 de Dezembro é permissível a entrada de estrangeiros por qualquer fronteira de Moçambique e que permite obtenção do visto em qualquer ponto. Por outro lado, as fronteiras moçambicanas são de fácil circulação pelo fato de não serem monitoradas rigorosamente.

O Centro de Refugiados de Maratane situa-se no distrito de Nampula ao norte de Moçambique. A sede deste, é a vila de Rapale. Este distrito localiza-se, aproximadamente, no centro da província que tem o mesmo nome, ocupando uma superfície $3.650 \mathrm{Km}^{2}$. Faz fronteira a este com o distrito de Meconta, a norte com os distritos de Muecate e Mecubúri, a sul com os distritos de Mogovolas e Meconta e a oeste com os distritos de

25 Governo do Zimbabué homenageia vítimas de massacre de lan Smith em Manica (16 de Abril de 2012), SAPONOTICIAS (htpp//noticias.sapo.mz/lusa/artigo/1459765.html (acedido no dia 16 de Dezembro de 2016). 
Ribáuè e Murrupula. Não é um distrito contínuo uma vez que dentro dele se encontra a cidade de Nampula, capital da província de Nampula, situada no entroncamento da linha férrea de Nacala com os eixos rodoviários que a ligam às províncias da Zambézia, Cabo Delgado e Niassa.

O Centro de Refugiados de Maratane localiza-se acerca de $30 \mathrm{Km}$ da cidade de Nampula, na localidade de Naburi Momola, do posto administrativo de Anchilo. $O$ atual centro de acolhimento de população refugiada situado em Maratane foi um local que, outrora, acomodava população portadora de deficiência física, doentes e população desamparada. Este centro recebia assistência médico-sanitária, alimentar e outras necessidades básicas através do Arcebispado de Nampula. Foi no ano de 2002 que o mesmo passou a acomodar população refugiada, uma vez que os centros de Bobole em Marracuene e Massaca em Boane (figura 3) ambos na província de Maputo, foram encerrados para a recepção dos mesmos.

Figura 3. Localização do antigo Campo de Refugiados de Bobole na Província de Maputo. Fonte: Adaptado pela a autora (2018).

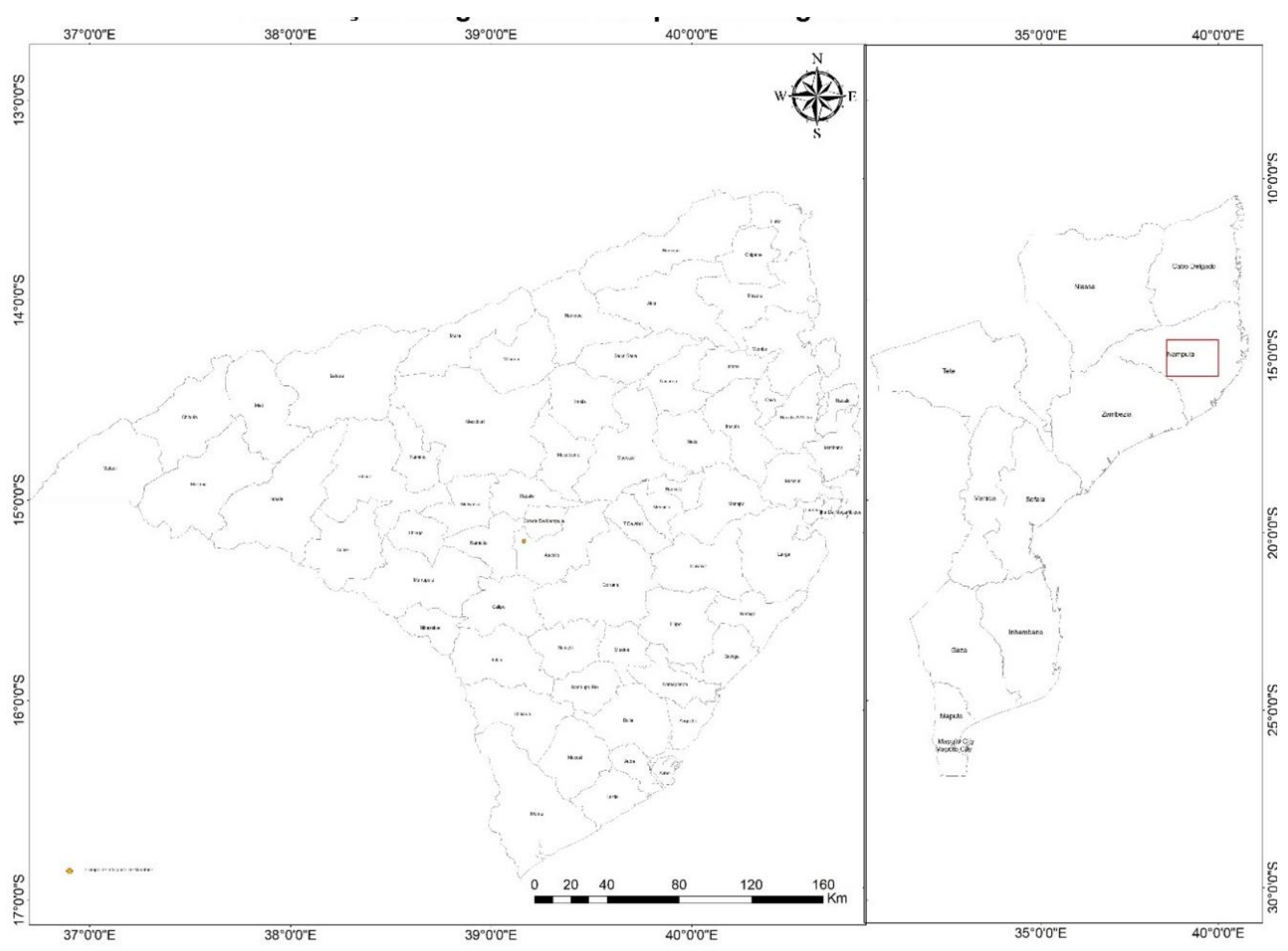




\section{POPULAÇÃO REFUGIADA EM MOÇAMBIQUE: DO CAMPO DE REFUGIADOS DE BOBOLE E MASSACA AO CAMPO DE REFUGIADOS DE MARATANE}

Como foi mencionado antes Moçambique tem na sua história o acolhimento de populações em perigo e que buscam segurança nele. Curioso é que apesar de se tratar de um país que ainda não encontrou uma paz efetiva ainda assim, algumas pessoas vêm o país como um lugar seguro. Os argumentos são vários, porém, o fato é que, os mesmos que uma vez dentro do país passaram por experiências de reassentamento. Inicialmente, foram acomodados no sul de Moçambique nos Campos de Refugiados de Bobole e de Massaca ambos localizados no sul de Moçambique e posteriormente (no ano 2001) foram transferidos para Maratane, no norte de Moçambique.

Entretanto, o número real sobre refugiados é variável, e os dados do Instituto Nacional de Apoio aos Refugiados (INAR) apenas se limita as pessoas que vivem no campo. Informação obtida em trabalho de campo realizado na cidade de Nampula e na Cidade de Maputo indicam que, existe um número incontável de pessoas que vivem em Moçambique e que chegaram como fugitivas. Estas pessoas conseguem viver na cidade, porque se casaram com moçambicanos e estabeleceram os seus negócios (Entrevista com Ser. Sudeca Novela, presidente da Associação Mukhero ${ }^{26}$ ).

Até finais de 2000 havia em Moçambique dois campos de refugiados: Bobole (há cerca de $40 \mathrm{Km}$ à norte da Cidade de Maputo) e Massaca (há cerca de $30 \mathrm{Km}$ da Cidade de Maputo). Ambos campos foram criados nos anos 1990 em resultado da piora da situação política na região dos Grandes Lagos da África.

Esta situação provocou de acordo com Oucho (2006) milhões de pessoas em situação de pessoas deslocadas internamente e outras como refugiados. Ainda o mesmo autor, a gênese dos problemas nesta região da África oriental e central resultou de golpes de Estado no Burundi e Ruanda imediatamente a seguir as independências destes países. Ambos os países passaram a "produzir" refugiados para a República Democrática do Congo (também país em guerra), Tanzânia e Uganda. Vale também referir que no ano 1994, Ruanda testemunhou a história mais dramática da África pós-colonial, onde em cem dias foram mortas 800 mil pessoas por conflitos étnicos.

O grupo étnico hutu matou a minoria tutsi. A racionalidade deste genocídio (como é conhecido nos relatórios das Nações Unidas) tem a ver com o fato de a minoria tutsi ter dominado durante muitos anos a maioria hutu. Enquanto acontece o genocídio nesta região, também no chamado Corno de África a situação não melhora desde a queda do imperador Hailé Selassié. Esta situação também, produziu pessoas em risco de

\footnotetext{
${ }^{26}$ É associação de comerciantes transfronteira. O movimento transfronteira surgiu no contexto de facilidade de fronteira entre Moçambique e o Reino da Swazilândia durante a guerra dos 16 anos. É corruptela da expressão em inglês "May you carry this bag?" (Pode segurar esta pasta ou sacola? Para evitar pagar taxas alfandegárias).
} 
vida e que foram descendo em direção ao sul de África até atingir Moçambique. Reconhece-se também, que com a queda do Apartheid na África do Sul no início dos anos 1990, muitos africanos passaram a ver este país como destino final.

Se por um lado poderiam ter acesso a segurança e integridade física, porque se encontravam muito distantes dos países de origem, por outro, teriam segurança econômica, considerando que a África do Sul se trata de um país economicamente forte a nível de África e as condições acadêmicas (universidades mais bem cotadas de África) e infraestruturas de saúde.

O estudo realizado em Maratane pelo então Centro de Estudos da População da Faculdade de Letras e Ciências Sociais da UEM no ano 2004, indicava na altura que os requerentes de asilo tinham como desejo chegar na África do Sul, pois sabiam que havia facilidades de acesso ao emprego. Entretanto, o mesmo estudo indica que algumas destas pessoas que tinham se aventurado em chegar a África do Sul tiveram que regressar à força por via deportação após uma experiência de detenção no centro de Repatriamento de Lindela (Lindela Repatriation Centre), sob acusação de ladrões de carros, assassinos, traficantes, raptores, estupradores, entre outros males.

Como acusam as organizações anti xenofobia, os requerentes de asilo ou estatuto de refugiado são vistos pela sociedade sul-africana e alguns políticos como a causa da desgraça na África do Sul. Uma das consequências desta situação informação não oficial disse que o Governo de Moçambique sob pressão de países vizinhos foi pressionado a restringir o movimento de refugiados para o sul de Moçambique e muito menos para a cidade de Maputo. Foi sob estas circunstâncias que os Refugiados dos campos de Bobole e Massaca foram relocalizados em Maratane no norte de Moçambique, conforme figura a seguir:

Figura 4: O atual campo de refugiados de Moçambique Fonte: Adaptado pela a autora (2018). 
Por altura do encerramento dos campos de refugiados cerca de 1.600 refugiados foram enviados para Maratane em voos charter do UNHCR e o Governo de Moçambique (Sá Consolo 2015) alguns refugiados resistiram a relocação pois queriam permanecer em Maputo. Porém, os que foram autorizados a ficar apenas os que tinham documentos de autorização ou de estatuto de refugiado. Esta resistência a um novo reassentamento tem a ver com o trauma que o processo está associado ao processo de reassentamento e considerando que estão próximos do país de fuga e ainda o fato de em pouco tempo terem se instalado e iniciado a organização de suas vidas.

Durante estas movimentações é natural que alguns tenham fugido para outros países, ou alguns conseguiram por vias não oficiais se instalarem. $\mathrm{O}$ artigo não procura analisar a questão da legalidade das suas movimentações, mas trazer ao de cima que as permanentes movimentações não permitem a formação de um espaço consolidado e, muito menos, garantem a resiliência que se pretende que as pessoas a tenham após um choque.

\section{CAMPO DE REFUGIADOS DE MARATANE: UM ESPAÇO EM PERMANENTE MUTAÇÕES}

O campo de refugiados de Maratane foi criado em 2001, no âmbito de transferência dos refugiados de Bobole e Massaca para longe da capital e da fronteira com a África do Sul. São cerca de 2500 Km que separam o novo campo e os anteriores. Na verdade a vida de refugiado é caracterizada por constantes movimentações. 
Nunca se sabe onde estará no dia seguinte. A única certeza que tem é que se está naquele lugar, naquele momento a viver de favores, e o amanhã depende do que os políticos farão. Disse um antigo refugiado moçambicano no Malawi entrevistado em $2005^{27}$ "só Deus sabe como será o amanhã e vive-se de incertezas, disse outro".

Se os moçambicanos viveram como refugiados no estrangeiro aprenderam técnicas de organização da produção assim como ensinaram a população de acolhimento sobre como organizar a produção e como fazer o armazenamento para que os bichos não ataquem os cereais. Nestas circunstâncias não se garante segurança produtiva e muito menos de assentamento. Moçambique tem sido considerado mesmo pelos refugiados de Maratane como sendo um país acolhedor, apesar de muitas dificuldades que passam. Como o Senhor Guterres antigo Diretor geral do UNHCR em Maputo no dia 21 de Agosto doe 2007, que Moçambique é um bom exemplo de acolhimento de refugiados. Neste campo são encontrados refugiados dos seguintes países: Burundi, Ruanda, Zimbabwe, Uganda, Sudão, Angola, Bangladesh, Afeganistão, Somália, Serra Leoa, Cuba e Palestina. Entretanto, o maior número é formado por refugiados da República Democrática do Congo e do Ruanda.

\section{A PROTEÇÃO DE REFUGIADOS EM MOÇAMBIQUE}

A semelhança dos países que assinaram a Convenção das Nações Unidas sobre os refugiados, é o fato de os refugiados estarem sob proteção dessa convenção de 1951, ratificada pelo Governo de Moçambique me 1975. Mas os mesmos são, também, cobertos pela Lei da Migração que regula a permanência dos estrangeiros em Moçambique.

A história do refúgio em Moçambique é continuada e tem a magnitude que tem dadas as condições objetivas criadas em Moçambique para receber os refugiados da Região dos Grande Lagos, que se encontram dentro do papel de apoio nas intervenções regionais no contexto da Convenção segundo a União Africana.

Quando os requerentes de asilo atravessam as fronteiras moçambicanas são registados e podem viver com o estatuto de residência temporária. É dada uma Declaração ${ }^{28}$, muitos refugiados, mesmo aqueles que vivem mais de 3 anos em Moçambique continuam a ostentar esta Declaração. Um estudo não publicado feito pelo Centro de Análise de Políticas da Faculdade de Letras e Ciências Sociais da UEM indica que por causa

\footnotetext{
27 Esta entrevista foi realizada em Lissiete, distrito de Mandimba na província do Niassa quando estava a recolher dados para a minha tese de doutoramento aos 22 de Maio de 2005.

28 É um pedaço de papel com nome e fotografia, que indica que eles declararam ser requerentes de asilo ou de refúgio. Este papel tem a validade de 2 meses, e então deve ser renovada.
} 
desta demora em autorizar o estatuto de refugiado, alguns deles, se envolvem ou atos ilícitos tais como aquisição de documentação falsa, incluindo certidão de nascimento e bilhete de identidade.

Gerir refugiados ou população refugiada tem sido um dos grandes desafios que qualquer país pode enfrentar. Se por um lado os países têm que olhar pela segurança das pessoas em perigo e olhar pelos problemas locais ou nacionais com suas populações, existe o problema de algumas destas pessoas que buscam refúgio não o serem na realidade, mas fazerem parte de grupos de criminosos que traficam armas e se aproveitam de as possuírem para praticar atos criminais tais como caça ilegal, furtos e assalto à mão armada ${ }^{29}$.

\section{PRODUZINDO E RECEBENDO REFUGIADOS EM MOÇAMBIQUE}

Foi em 22 de Outubro de 1983 que o Governo de Moçambique assinou a Convenção das Nações Unidas sobre os Refugiados e também ratificou a Convenção da extinta Organização da Unidade Africana (OUA) que indica aspectos específicos sobre os refugiados africanos. Desde 1986, o país tem permitido a entrada de pessoas que buscam proteção e com todos os direitos preconizados na Convenção, nomeadamente non refoulement ${ }^{30}$, habitação, emprego, assistência médica, etc.

A UNHCR reconhece em Moçambique um campo de refugiados: Centro de Maratane, em Nampula, onde viviam em no ano 2015 cerca de 8 mil pessoas requerentes do estatuto de refugiado e de asilo. Este centro, serve apenas para recepção e registo de pessoas que lá se apresentam. Ele é aberto e as pessoas acomodadas nele mantêm contato direto com as comunidades à sua volta. E estas comunidades beneficiam de infraestruturas de saúde e de escola.

\section{MOÇAMBIQUE PAÍS DE REFÚGIO: ESCOLHA INTENCIONAL, OU POR ACIDENTE?}

O relatório do ACNUR de 2000 refere que os principais fluxos de refugiados para Moçambique começaram em meados dos anos 70, à medida que, se intensificavam os conflitos armados no continente africano e, em particular, na região austral de África. Pelos finais da década de 1970 o ACNUR calculava em cerca de 14.500 o número de refugiados da então Rodésia do Sul (atual Zimbabwe) em Moçambique de um conjunto de 210.000 refugiados existentes em Moçambique, no Botswana e na Zâmbia. Em 1980 o Zimbabwe tornou-se independente e, a partir daí, se tornou país de acolhimento para um número crescente de refugiados moçambicanos, produto da guerra dos 16 anos ocorrida entre 1976 e 1992.

\footnotetext{
${ }^{29}$ Tem sido reportado pela imprensa moçambicana que o crescente número de caçadores furtivos e cortadores de árvores para o comércio internacional da madeira nas províncias de Nampula e Niassa têm relação com pessoas que pedem asilo em Moçambique.

30 Os países de asilo se obrigam a não enviar as pessoas para onde têm receio fundado de perseguição (ACNUR, 2000, p. 02).
} 
Nas últimas duas décadas, Moçambique tem recebido um relativo crescente número de pessoas que atravessam as fronteiras a partir das províncias do norte, Niassa e Cabo Delgado e de províncias do centro tais como Zambézia, Tete e Manica e no sul através das províncias de Gaza e Maputo. São praticamente todas as províncias com fronteiras terrestres com outros países africanos. Estas pessoas, através de seus relatos dizem que fogem perseguições nos seus países e incluindo conflitos armados. São pessoas provenientes da Somália, Sudão, Burundi, República Democrática do Congo e Etiópia. Também, o país tem recebido pessoas que se declaram nacionais de Líbano, Bangladesh e Paquistão. Muitos deles são apanhados pela Polícia da República de Moçambique e conduzidos para as esquadras da polícia, ou em alguns casos os mandam diretamente ao Campo de Refugiados.

Em estudos realizados em outros contextos os requerentes de asilo e, posteriormente, refugiados dizem que não escolheram Moçambique como o destino final, mas um país em trânsito, porque pretendem chegar à África do Sul, país com mais oportunidades, mas também, existem os que tiveram experiência na África do Sul e optaram por voltar a Moçambique, porque dizem não sofrer ataques xenófobos e haver mais oportunidades de fazerem negócios do que na África do Sul ou outro país africano da região austral da África.

O estudo realizado por Raimundo (2010) indicou as seguintes razões: a) a paz efetiva em Moçambique após a Guerra devastadora que durou 10 anos e que opôs o Governo da FRELIMO ${ }^{31}$ e o movimento armado da RENAMO ${ }^{32}$; b) o campo de refugiados é aberto diferentemente da Tanzânia e do Quênia onde, as pessoas são confinadas em um espaço e sem poderem se movimentar. Em um campo aberto eles podem sair e fazer os seus negócios e venderem os seus produtos resultantes da alfaiataria, costura, corte de cabelo e também procurarem empregos na cidade incluindo, viajar até Maputo a capital de Moçambique e fazer agricultura; c) o fato de alguns países africanos terem fechado as suas fronteiras como medida preventiva contra entrada de população refugiada. É o caso da Tanzânia que fechou a fronteira com o Burundi em 1994. O fechamento da fronteira restringiu o acesso de pedidos de asilo e de movimentação de pessoas em busca de refúgio em outros países; e d) possibilidades de se conectarem com os seus familiares que se encontram há mais tempo em Moçambique e que vieram como refugiados. A entrada foi facilitada pelos seguintes fatores: i) o fato do Governo de Moçambique permitir que qualquer cidadão possa pedir visto de entrada em qualquer fronteira, sem necessariamente ter que pedir em uma embaixada ou consulado; ii) as fronteiras não são monitoradas constantemente existindo, em alguns casos, lugares onde os marcos foram retirados assim como o arame farpado.

Esta situação acontece nas fronteiras com a República do Malawi, República do Zimbabwe e da Tanzania. Aliás, o caso do Malawi é uma situação que existe desde o período colonial, onde a fronteira com

\footnotetext{
31 Frente de Libertação de Moçambique.
}

32 Resistencia Nacional de Moçambique. 
Moçambique é estabelecida através de estradas ou caminhos. Algumas dificuldades encontradas têm a ver com a língua uma vez que muitos deles são provenientes de países de expressão francesa (Congo e Burundi), aramaico (Etiópia), árabe, mandarim e paquistanês, etc.

\section{MOÇAMBIQUE PAÍS PRODUTOR DE REFUGIADOS E RECEPTOR DE REFUGIADOS}

Em 1992, ano em que a guerra terminou em Moçambique, havia mais de 1 milhão de moçambicanos refugiados em diversos países da região, aonde pediram refúgio de asilo (ACNUR, 2000). Estima-se que após a assinatura do Acordo Geral de Paz foram repatriados 1.700 .000 moçambicanos como se pode observar na tabela (2).

Tabela 2. População repatriada após a guerra. Fonte: ACNUR, 2000; Raimundo (2008; 2010).

\begin{tabular}{cc}
\hline País de refúgio & Número de população retornada \\
\hline Tanzânia & 58.000 \\
Malawi & 1.285 .000 \\
Zâmbia & 22.000 \\
Zimbabwe & 247.000 \\
África do Sul & 71.000 \\
Swazilândia & 17.000 \\
Total & 1.700 .000 \\
\hline
\end{tabular}

Do conjunto de países de refúgio a República do Malawi foi o país que mais moçambicanos recebeu como pode ser observado na tabela (3)

Tabela 3. Refugiados Moçambicanos em Malawi entre 1988 e 1992 Fonte: Babu and Hassan 1994:235 (Tabela 1) e Raimundo (2010).

\begin{tabular}{|c|c|c|c|c|}
\hline \multirow[t]{2}{*}{ Distrito } & \multicolumn{2}{|c|}{ Refugiados } & \multirow[t]{2}{*}{ População malawiana em 1992} & \multirow[t]{2}{*}{ Fator de stress* } \\
\hline & 1988 & 1992 & & \\
\hline Nsanje & 219243 & 291518 & 223654 & 130 \\
\hline Mwanza & 21839 & 87975 & 140439 & 63 \\
\hline Mulanje & 40745 & 51890 & 739243 & 7 \\
\hline Thyolo & - & 39819 & 499763 & 8 \\
\hline Chikwawa & 31032 & 87982 & 370337 & 24 \\
\hline Mangochi & 27088 & 44434 & 574272 & 8 \\
\hline Machinga & 13985 & 27396 & 595920 & 5 \\
\hline Ntcheu & 135788 & 137072 & 416472 & 33 \\
\hline Dedza & 120570 & 153059 & 475800 & 32 \\
\hline Lilongwe & 26748 & 38565 & 1423358 & 3 \\
\hline Mchinji & 3129 & 21039 & 287394 & 7 \\
\hline Nkhata-Bay & 487 & 4395 & 157552 & 3 \\
\hline Total & 640167 & 985144 & 5904204 & 17 \\
\hline
\end{tabular}


De acordo com os autores o "fator de stress" é expresso em número de moçambicanos existentes no distrito por cada 100 malauianos. O fator de stress varia de 3 para 130 em 1992, refletindo a extensão da presença e influência da população refugiada em relação a população local.

Como foi previamente mencionado Moçambique é país produtor e também receptor de refugiados. $E$ nestas circunstâncias, recebe pessoas com várias características de organização do seu espaço produtivo. A relação de muitos anos entre a população local e a refugiada tem mantido e criado uma característica peculiar de organizar o espaço.

\section{ESPAÇO INCOMPLETO MOLDADO PELO NOMADISMO}

Ao observar esta história incontável de movimentações por parte de moçambicanos ou de outros povos que buscam Moçambique como país de segurança, a questão que pode ser colocada é a seguinte: como é que o espaço pode ser construído na condição de nomadismo, não obstante nestes lugares onde esta situação acontece serem ricos em recursos naturais, nomeadamente solos férteis, água, florestas e recursos minerais? A discussão deste assunto revela-se bastante ousada uma vez que em Moçambique o debate sobre espaço geográfico é ainda incipiente, e ainda discutir sobre processos inconclusivos ou não consolidados desse espaço. Neste trabalho começaria por discutir o conceito de espaço e como ele é formado, ao mesmo tempo em que se reconhece a fraca base teórica sobre "formação do espaço no contexto da mobilidade".

Vale afirmar que o espaço é formado, à medida em que, os homens e mulheres se relacionam com os recursos naturais, neste caso o solo, a água, os minerais, a terra para construção. Também se reconhece que a formação do espaço é um processo inconclusivo não só pelos argumentos da mobilidade humana, mas sim, pelo conhecimento ou grau de conhecimento e de valorização desse recurso. Também, refere-se que a sua formação vai depender do grau de sedentarismo, pois um povo em permanente mobilidade pode começar e não concluir, e depois começar e não concluir em outro lugar.

Isso seria uma analogia ao tipo de espaço que os povos nômades da atualidade tais como: os Tuaregues, os Beduínos, os Massai, e os bosquímanos constroem. Porém, enquanto aqueles a mobilidade é "controlada e gerida" por fenômenos naturais (busca de pasto, por exemplo) aqueles que temos estado a discutir são movidos por fenômenos naturais (cheias, secas, ciclones e aluimento de terras), fenômenos políticos (guerras e perseguições) e econômicos (projetos de desenvolvimento). Outro fato que os distingue é por serem orientados onde fixar residência e como produzir no novo assentamento ou no lugar de acomodação, enquanto os outros ainda são guiados pela orientação do seu líder e, com intervenção mínima do Governo. 
Não existem estudos empíricos para o caso de Moçambique capazes de sustentar o tema em debate, e de permitir fácil compreensão desta relação migração ou permanente nomadismo e formação do espaço. A falta de interesse neste assunto é porque a migração é um assunto que se restringe apenas em torno de migrações internacionais, soberania e segurança dos Estados, controlo cerrado das fronteiras internacionais, rápida urbanização, pobreza urbana, tráfico de pessoas, etc. Até onde pesquisamos, não foram encontrados estudos que apresentem de forma implícita a relação entre fenômeno e a inconclusão da formação do espaço. Alguma experiência sobre estudos de migrações forçadas, fundamentalmente as histórias de vida, grupos focais de discussão e observação trouxeram ao de cima uma questão que, não tendo merecido a devida atenção dos diferentes pesquisadores moçambicanos, nos obrigou a observar e a analisar com muito cuidado.

Trata-se da formação do espaço no contexto de mobilidade. Olhando atentamente para o número de casos de pessoas que se sentiram obrigadas a mudar de residência (temporária ou definitivamente), notamos que se tratava de fato de um fenômeno que merece alguma atenção. De que espaço estaríamos falando?

As histórias de vida da população ou dos agregados familiares entrevistados, permitiram-me perceber a existência de um processo que nunca chega a ser concluído, porque o produtor está em permanente mobilidade. É importante observar que, as famílias que vivem em áreas de risco de calamidade foram criando ao longo do tempo uma espécie de "dois espaços de vida": o lugar de refúgio que pode ser o mato, a área alta, a cidade próxima, ou país vizinho, o lugar de reassentamento e o lugar de residência habitual, que é a terra que lhe pertence, cujo tempo de vivência pode variar entre 4 a 8 meses. É curioso notar que as pessoas acabam por definir o local de acomodação temporário ou de reassentamento não como o seu espaço definitivo e, por isso, sem grandes investimentos e organizado apenas para as necessidades diárias porque garante a proximidades com a escola dos filhos, posto de saúde ou ainda com a cidade grande.

Interessantemente é que os emigrantes que saíram devido a qualquer uma das causas, nomeadamente conflitos políticos, cheias, seca, etc., quando regressam as suas terras de origem, podem com certa relatividade recuperá-las. Estudos sobre migrações em Moçambique têm como foco o trabalho migratório, os refugiados de guerra e comércio transfronteiriço e pouco sobre o impacto que as mesmas podem formar espaços inconclusivos.

Tal como já nos referimos, a mobilidade ou nomadismo e a formação de espaços inconclusivos constituem a questão central deste trabalho. Neste contexto, entendemos por mobilidade ou nomadismo a todo o movimento de pessoas que é feito em decorrência de um fator de força tal como a guerra, calamidades naturais e projetos de desenvolvimento e, por isso, as famílias são forçadas a sair temporariamente excluindo neste caso, viagens turísticas desde que tenha intenção de regressar ao ponto de origem. O espaço e sua formação. O espaço social corresponde ao espaço humano, lugar de vida e trabalho: morada do homem, sem 
definições fixas. O espaço geográfico é organizado pelo homem vivendo em sociedade e, cada sociedade, historicamente, produz seu espaço como lugar de sua própria reprodução conforme aponta, Saquet e Silva (2008). A mobilidade e a formação do espaço se inter-relacionam, uma vez que as pessoas em movimento criam espaços e as características destes podem impulsionar ou não o movimento das pessoas.

É de reconhecer o papel das movimentações na formação do espaço e está na distribuição e redistribuição geográfica da população e dos assentamentos e dos lugares de produção. Enquanto, uns procuram ter uma fixação definitiva, outros olham para aquele lugar como temporário. Entretanto, deve-se reconhecer que enquanto o governo considera os lugares de reassentamento como definitivos e por isso, o encorajamento de iniciativas locais para a construção de infraestruturas, permitindo desta forma, uma paisagem distinta e com características específicas. O campo de refugiados, por exemplo, é exemplo destas características, pois desde que foi estabelecido em 2001 passam 15 anos e os moradores não obstantes serem pessoas que são substituídas regularmente, criam novos espaços produtivos em harmonia com as comunidades locais. Entretanto, os moçambicanos nos campos de acomodação vivem da ajuda e nos bosques enquanto se escondem vivem do que vão colhendo (frutos silvestres) ou caçando.

No geral, Moçambique continua em termos de desenvolvimento com grandes fossos humano e social. Esforços do governo de Moçambique e da comunidade internacional têm redundado em fracasso porque a pobreza em Moçambique diminui de forma lenta sendo um dos sinais o incumprimento dos Objetivos de Desenvolvimento do Milênio.

Uma análise mais geral, demonstra que os fatores identificados pelos relatórios acima referidos são os que caracterizam o estado de pobreza na sua generalidade em Moçambique. Porém, podemos encontrar dentro das comunidades rurais outros fatores que põem em causa todo o esforço que o governo moçambicano e os doadores têm desenvolvido na erradicação da pobreza. Um dos fatores de maior relevância é a incapacidade da população concluir o seu espaço produtivo e residencial devido ao estado de nomadismo. $\mathrm{O}$ nomadismo não só impede que a população em áreas de risco natural, econômico e político tenha iniciativas próprias para a erradicação da pobreza, como também condiciona a permanência destas nas suas áreas de residência, impedindo que elas tenham tempo suficiente para a produção da sua subsistência e de excedentes para o mercado.

\section{CONCLUSÃO}

O nomadismo é uma forma de defesa e é facilitado pela a existência de mato e montanhas (onde as pessoas facilmente se escondem), por terra que ainda existe a disposição não obstante os projetos de 
desenvolvimento (os megaprojetos) e pela ajuda internacional ainda possível nos campos de acomodação ou de reassentamento. Porém, toda esta movimentação afeta em muitos aspectos a vida das famílias e consequentemente:

- na segurança de posse da terra, à medida em que a mobilidade permanente obriga a ocupações de várias terras;

- na forma de cultivo, ou outras formas de organização da produção. Geralmente em situação de nomadismo pratica-se agricultura de subsistência e raramente para o mercado; e a situação agrava-se quando se é refugiado.

- na segurança alimentar que não é assegurada a medida em que mudam de terras de cultivo em função do fenômeno. Segundo as pessoas acomodadas no Campo de Acomodação de Chihaquelane na província de Gaza é mais fácil recuperar pós-cheias do que pós conflito. Pois não se sabe se a guerra acabou ou não. Temos ouvido rumores em Muxúngoè de que a situação não está bem. Então, como é que uma família pode construir a sua casa ou pensar em ter uma machamba grande onde possa produzir o que quer?

-no rendimento escolar das crianças, à medida em que não têm um lugar permanente onde possa estudar; e

- organização social coerente das famílias.

\section{REFERÊNCIAS}

INACE , 2013.

Meccagni, A. L. Reducing refugee rights? A comparative analysis of shifting refugee policy and practice in Mozambique and Guinea. Master of Arts in Law and Diplomacy thesis. Unpublished MA thesis, Tufts University, 2005.

Raimundo, I. M. Mozambican refugees in Malawi: Did the Malawians gain the hell? Comunicação apresentada na "International Conference on Environment, Forced Migration \& Social Vulnerability" organizada pela United Nations University of Bonn, Bonn, 9-10 October. Comunicação não publicada, 2010.

Raimundo, I. M. International Migration Management and Development in Mozambique: What Strategies? International Migration Vol. 47 (3), 2009.

Shaklands, Alex and Gonçalves, Euclides, Imaging agricultural development in South-South Cooperation: The contestation and transformation of ProSAVANA. World Development Vol. XX, 2016.

\footnotetext{
i Instituto Nacional de Apoio às Comunidades Moçambicanas no Exterior.
} 